\title{
Reclaiming Tutorials as Learning Spaces in the Sciences
}

\section{Ina Louw*}

Department for Education Innovation, University of Pretoria, Hatfield, Gauteng, South Africa

* CONTACT Ina Louw ina.louw@up.ac.za

Department for Education Innovation, University of Pretoria, Lynnwood Road Pbag x 20, Hatfield, Gauteng 0028, South Africa 


\begin{abstract}
Tutorials/discussion classes ${ }^{1}$ are seen as an essential part of the teaching mix in the natural sciences, because that is where problems can be solved and course content is applied. Learning support provided by teaching assistants may free up the lecturer to do research, but are these assistants sufficiently well trained and well informed? Do tutorials offer learning spaces or merely activities to engage the willing student? In this paper I report on a study conducted in a science faculty of a research intensive university in South Africa. I collected data using interviews and questionnaires which gave insight into the many variants of tutor/teaching assistant ${ }^{2}$ support that exist in the faculty. Practices that seem to lead to better student learning were also foregrounded. It became evident that lecturers need to plan their tutorials as an integral part of the learning space and not as an add-on activity.
\end{abstract}

\title{
Key Words
}

Science, tutorials, tutor training, assessment in tutorials, Zone of Proximal Development

\section{Introduction}

"Learning is not a spectator sport" and students need to make what they learn a part of themselves (Chickering \& Gamson, 1987, p. 4). This notion is best exemplified in a best practice tutorial session, where the group is smaller (20 students per tutor) and knowledge is applied (Arand, 2014; Louw, 2003; McDermott, Shaffer \& Constantinou, 2000; Papinczak, Tunny, \& Young 2009). The current massification of Higher Education is another factor mentioned by scholars in favour of tutorial sessions (Ghosh, 2007; Underhill \& Mc Donald, 2010). It is generally accepted that the natural sciences cannot successfully be taught without tutorials, as that is where problems can be solved and the content can be applied (Brogt, 2007; Caldwell, 2007; Ghosh, 2007). However, there is not one single best method for science tutorials (Ghosh, 2007), and best practices are not usually shared amongst colleagues in a discipline. The design and purpose of a tutorial session cannot be underestimated, as that determines the lecturer's stance on this learning space. Unfortunately, the pressures on permanent academic staff to produce research outputs leads to practices where tutors are left in charge of the tutorials (which is seldom good practice) without enough support from the staff; consequently optimal learning may not take place during these sessions (Brockbank \& McGill, 1998).

In this paper, Vygotsky's Zone of Proximal Development (ZPD) (1979) is used as a theoretical framework and an explanatory tool (Murphy, Scantlebury, \& Milne, 2015). The Zone of Proximal Development is often simplistically seen as the gap between what students can achieve on their own, compared to achievement with teacher assistance, but Palincsar (1998) argued that the ZPD is more than an explanatory tool. The ZPD has a "descriptive power in terms of the use of cultural tools and artefacts that mediate learning in the ZPD" (Palincsar, 1998:370).

As the staff developer for a science faculty of a research intensive university in South Africa, I was tasked with conducting a survey about tutorial provisioning in the faculty. As the researcher, I would be regarded as an informed outsider, because I am not a staff member of the faculty; yet as their designated academic developer, I have access to information and people and am treated as a staff member. I collected data using interviews and questionnaires which gave insight into the many variants of tutor support that exist in the faculty, for example,

\footnotetext{
${ }^{1}$ In South Africa the term tutorial is used to describe discussion classes, and I will use the term tutorial in this paper.

${ }^{2}$ The term tutor will be used (in line with South African nomenclature) to refer to teaching assistants.
} 
completing exercises beforehand or during the tutorial; writing a test at the end, or not; including online activities, or not.

To understand the context, it is important to realise the magnitude of the tutorial provisioning in the faculty. Table 1 shows the quantitative reality. Arising from the size of the faculty (17 departments), it is divided into four clusters, i.e. Mathematical, Physical, Agricultural and Biological: the data will be reported as such.

Table 1. Overview of Enrolments for Tutorials in the Faculty

\begin{tabular}{ll}
\hline Cluster (number of departments included) & $\begin{array}{l}\text { Total number of students served by tutors } \\
\text { and demonstrators* }\end{array}$ \\
\hline Mathematical (3) & 31755 \\
Physical (4) & 19331 \\
Biological (5) & 14556 \\
Agricultural (5) & 6126 \\
\hline
\end{tabular}

Total departments: 17

71768

* If a student is enrolled for four modules, he/she is counted in each module total as receiving tutorials and/or practicals. Some modules are offered to students from other faculties as well.

Firstly, I will briefly sketch South African higher education contexts and then specifically the context of the study site. Then I outline tutorials as integrated learning spaces with reference to the literature. Subsequently I share and discuss the findings from the study and offer recommendations for good practice.

\section{Higher Education in South Africa}

South Africa is still struggling to improve the quality of education in schools disadvantaged during apartheid, twenty-two years after the inception of democracy. The quality of the exit examination in Grade 12 is considered in many quarters to be questionable and marks are increased annually to satisfy political goals (Swanepoel, 2016). This practice of inflating marks creates unrealistic expectations amongst the learners, as well as an inflated sense of academic capability. Universities often overestimate the prior knowledge of new entrants and this mismatch contributes to high failure rates in first-year courses (Van Wyk, Hofman \& Louw, 2015). Universities enroll an increasingly diverse cohort of students every year (Underhill \& McDonald, 2010) in terms of academic ability, culture, language and study habits. This situation means that effective tutorials are even more crucial, as that is where students are grouped in smaller numbers (Finkelstein \& Pollock, 2005; Ghosh, 2007) and can be guided to make sense of the work (Steinberg, 2000), practice their skills (Finkelstein \& Pollock, 2005), cultivate critical thinking (Gilkison, 2003) and learn from and with each other (Brogt, 2007).

The Higher Education landscape in South Africa was substantially changed when different institutions were merged and new categories of universities were created, i.e., comprehensive (incorporating diplomas from previously designated technikons), universities of technology (more vocationally orientated) or traditional universities (Scott, 2009). Some of the traditional universities are considered to be research-intensive institutions, indicating that research is their highest priority and consequently, in some cases, teaching and learning is not seen to be as important as research.

The institution in question is a research-intensive university and the faculty is one of the best producers of research output for the university (University of Pretoria, 2016). However, the faculty has also prioritized teaching and learning, and the structure of the faculty management includes a Deputy Dean for Teaching and Learning; this portfolio is executed with dedication and enthusiasm, resulting in increased publication about lecturers' work within the scholarship of teaching and learning and an organized forum where teaching and learning 
ideas are exchanged. The university also embraces a hybrid mode of delivery, including online learning activities in most modules.

\section{Tutorials as Learning Spaces}

The notion that tutorials should be learning spaces is one that is fairly well accepted, but less is known about how this is achieved. I argue that a lecturer needs to have a clear picture of the purpose of the tutorial sessions, before they can be turned into a learning space. Tutorials can have many purposes, but tutorials in the sciences have historically been used to practise problem-solving (calculations) in mathematics, statistics, physics and chemistry (Caldwell, 2007; Ghosh, 2007). This task is often administered using a problem sheet that students are required to complete either before or during the tutorial session. This exercise is then discussed during the tutorial; however, it is said that the emphasis should not be on supplying the answers (Finkelstein \& Pollock, 2005), but on reasoning, discussing and arguing the answers (Steinberg, 2000). Similarly, Steinberg (2000) claimed that tutors should not teach, but rather guide/facilitate and supply feedback on students' attempts. This strategy suggests that it is important to rectify students' misconceptions during tutorials and that is why tutors should know what these misconceptions are, in order to "systematically elicit, confront and help students to resolve them” (Brogt, 2007, p. 52).

Students often enter higher education with a "hidden contract" (Brogt, 2007). According to this contract, they expect that they can memorize facts, reproduce them during tests and be awarded a good score. This is most likely because they often succeeded by following this approach during their school careers. Caldwell (2007) maintained that students need to learn that problem solving during tutorials is much more than covering the content, and it is an opportunity to obtain a deeper conceptual understanding thereof, as well as to discuss and reason with others (peer learning).

In the sciences, Finkelstein and Pollock (2007) argued that the tutorial group should be smaller to enable tutors to use a Socratic approach, but often the tutorial groups are too large to properly achieve this goal. In Finkelstein's study (2007) there was a ratio of 1:14 in the tutorial groups; however that is not possible anymore, particularly in the South African context, which suggests that we should rethink and redesign our tutorials. Caldwell (2007) offered some suggestions, based on the recognition that the Socratic approach does not work in large classes.

\section{Preparation and Skills of Tutors}

An important issue raised in the literature is how tutors can be prepared for tutoring (Arand, 2014; Finkelstein \& Pollock, 2005; Gilkison, 2003; Underhill \& McDonald, 2010). At a research intensive university, where postgraduate students are in abundance, there is no shortage of tutors with disciplinary knowledge, but is this enough? Gilkison (2003) noted that a tutor with pedagogical content knowledge (PCK) is preferable over a disciplinary expert without PCK; however that particular study was conducted in a problem-based learning (PBL) environment and its findings are not directly transferable to a tutorial. Gilkison felt that a skilled tutor would be better able to raise critical awareness, facilitate group processes and direct student learning (2003). In a similar study by Ghosh (2007) where a modified type of PBL (similar to tutorials) was conducted and functioned alongside normal lectures, it was found that students reported improved self-directed learning. The tutorial size was below ten per group, and student feedback was collected by means of a questionnaire with a 3-point scale at the end of each session; students reported that their learning was scaffolded, that they experienced increased peer interaction and perceived the "judicious mixture" of lectures and tutorials as ideal (Ghosh, 2007, p. 196). To facilitate optimal learning, it is claimed that tutors need to be skilled in communication, interpersonal and organizational skills, but that these skills do not come naturally to most tutors (Falchikov, 2001), and would need to be included in training. 
If one considers a tutorial through the lens of the Zone of Proximal Development (ZPD) (Vygotsky, 1979), it becomes even clearer that tutors need training to be able to make the most of tutorial sessions. Additionally, the increased class size necessitates new skills for tutors: Murphy et al. (2015) offered excellent advice. Their study focused on a co-teaching environment, where pre-service teachers were present in the class with the in-service teachers and shared the responsibility for all aspects of learners' learning for that period of time. The aim was to reflect on theory, practice and praxis in order to narrow the gap between theory and practice. Certain parallels can be drawn between Murphy et al's study and this one and these are presented in Table 2.

Table 2. Useful Constructs from the Study by Murphy et al. (2015, p.290) as Contextualized for this Study

\begin{tabular}{l|l}
\hline Construct & Application to this study \\
\hline $\begin{array}{l}\text { Co-planning: } \\
\text { interaction between } \\
\text { real and ideal forms } \\
\text { and buds of } \\
\text { development }\end{array}$ & $\begin{array}{l}\text { Students should come to tutorials prepared, having attempted the } \\
\text { homework. The focus is on learning, not completed tasks. Tutors } \\
\text { should come prepared, having planned how they will guide students } \\
\text { from real to ideal. Students are seen as "buds of development", } \\
\text { being near the next level and able to get there with assistance }\end{array}$ \\
$\begin{array}{l}\text { Vygotskian } \\
\text { emulation and unity } \\
\text { of affect and }\end{array}$ & $\begin{array}{l}\text { Vygotsky's notion of imitation is not to "copy", but to emulate, and } \\
\text { is part of this learning process. Emotions and learning are seen as } \\
\text { intellect }\end{array}$ \\
$\begin{array}{l}\text { interdependent. Emotional engagement is required for learners to } \\
\text { mistakes and recognize that their behavior determines their learning. } \\
\text { The tutor should be a role model to allow emulation and should be }\end{array}$ \\
$\begin{array}{l}\text { Co-evaluation: } \\
\text { regression and } \\
\text { recursion and } \\
\text { structured reflection } \\
\text { Learning does not always occur on an upward trajectory. Sometimes } \\
\text { regression and recursion is important so that students re-learn } \\
\text { something. It is a good practice to ask students to reflect on the } \\
\text { tutorial session and share their reflections. Tutors have to } \\
\text { acknowledge that learning is hard work. They too have to reflect on } \\
\text { their practice. }\end{array}$
\end{tabular}

Tutor training is mentioned as an important element of tutorial success (Arand, 2014; Finkelstein \& Pollock, 2005; Gilkison, 2003; Underhill \& McDonald, 2010) involving communication, questioning techniques, listening skills, presentation skills and the ability to handle student diversity (Underhill \& McDonald, 2010). The authors argued that to think that postgraduate students have all the content knowledge and therefore do not need extra training, is a false assumption. Furthermore, it is noted that although postgraduate students will surely serve to motivate undergraduates, they do not necessarily possess the required skills to encourage student learning and create a learning environment (Underhill \& McDonald, 2010). It is also important that tutors receive training on being sensitive to different learning styles (Bianco, 2005) and learn how to model reflective practice (Papinczak et al., 2009); however, equally important, is that tutors have a support structure where they can access information and advice (Arand, 2014).

\section{Tutorials and Assessment}

Brogt (2007) was very helpful in considering whether or not assessment should take place during tutorials. He referred to the tendency to use a test at the end of the tutorial session as a means of capturing attendance; but suggested that the mere inclusion of a test changes the purpose of the tutorial (Brogt, 2007). I interpret the academic task during a tutorial, as in 
Brogt's lecture-tutorials, as an opportunity to succeed in solving the problems at hand with the resources available (peers). However, the inclusion of assessment changes the academic task to finding the correct answer instead of developing thinking processes.

This change in focus links with a view held by Eun, Knotek and Heining-Boynton (2008). They explained a reconceptualization of the Zone of Proximal Development (ZPD) as proposed by Vygotsky (1979), which has so frequently been investigated in education literature (Ageyev, 2003). They claimed that apart from the first voice of the more capable participant (the tutor), who supports the learning, and the second voice of the less competent participant (student), "there is a third voice that serves as an immediate agenda of the ZPD" (Eun et al., 2008, p.135). Eun et al. saw a test as the third voice. They went on to say that progression through the Zone is determined by the compatibility of the agenda of the third voice, and the development goals of the Zone. In other words, if we claim that the tutorials are meant to develop students' reasoning skills, we should not measure their test taking skills.

The existence of the ZPD makes tutorials the perfect opportunity to scaffold students' learning, by asking strategic questions, ensuring learning on a metacognitive level, moving learning forward at an appropriate pace, assisting students with recognized misconceptions, challenging students' understanding, facilitating peer interaction and modelling and coaching (Papinczak, et al., 2009). Tutors should also know when to step aside as students become more competent. The notion of the ZPD has been used as a central theoretical frame for understanding the data and finding ways to support and encourage good practice.

\section{Research Design}

\section{Methods}

The descriptive case study design (Yin, 1984) was chosen to gather multiple perspectives in a real-life context towards a comprehensive and deep understanding of the phenomenon of tutoring (Nieuwenhuis, 2011). In this paper I report on part of a larger mixed-methods investigation at faculty level into the practical implementation of tutorials in a researchintensive university in a science faculty. Many questions were explored in the larger study, some of them for internal decision making, but the survey questions that will be focused on in this paper are: (a) How are tutorials structured/what approach do they follow? (b) What kinds of training and/or support exist for tutors? (c) Why do lecturers regard their tutorials as successful?

\section{Developing the questionnaire}

Qualitative interviews were held with the Department of Statistics as a strategy to guide the construction of the questionnaire which was to be administered to the whole faculty. Openended interview questions were constructed, such as "How are tutorials structured/what approach do you follow?" in order to ensure that all possible variations in tutorial provisioning would be captured. If incomplete descriptions were given, questions were used to probe further, such as: "how long and how often?” or "who is present?” or "what gets done?” The information from the interviews guided the construction of the final questionnaire. This process was followed in addition to an in-depth literature review in order to ensure that a valid instrument would be used when data were collected from the entire faculty. Qualitative data from the interviews and the open ended questions were coded using open coding, by allocating a code to each new/unique response, and subsequently constructing themes and categories. The quantitative data (descriptive statistics only) were captured in Excel and the normal functions were used to obtain descriptive statistics. The interviews can be seen as a pre-pilot phase; subsequently the questionnaire was also piloted with purposefully sampled individuals (critical friends) to ensure clarity of questions and that we obtained answers to the survey questions, thus ensuring reliability (Cohen, Manion \& Morrison, 2000). All the other data were collected 
using the questionnaire. The captured data were sent back to each respondent to verify its accuracy, and corrections were made where needed.

\section{Participants}

The Deputy Dean for Teaching and Learning announced the survey to the 17 heads of departments during a meeting, to ensure full participation. In addition, the very large departments such as Mathematics, Chemistry and Physics were visited so that we could explain the importance and urgency of the study, in order to ensure cooperation, as the first goal of the survey was to understand what is on offer currently so as to plan and design improvements to support our students further. There was no sampling in terms of the departments or modules, since we needed information from all. Departments participated in different ways, but data were obtained from every department. Some departments decided that the module coordinator, rather than every staff member, would supply all the information, which could be seen as a form of purposive sampling (Cohen et al., 2000), but this approach was not uniformly followed: in smaller departments I collected information from individual lecturers. The questionnaire was completed for a module and if multiple lecturers were involved, and deviations existed in their tutorial provisioning, the differences were requested from the module coordinator. Staff members were not forced to participate, but because they are the owners of the data, needed for future planning for the institution, they felt an obligation to participate.

The quantitative data were captured in Excel, and the general functions in Excel were used to obtain the descriptive data that will be reported in this paper. I realized that since practical sessions are an integral part of the teaching approach, some departments could not distinguish clearly between tutorials and practical sessions as there seems to have been a blending/merging of the two approaches. For the open-ended questions, coding was undertaken, and themes were identified using Tesch's method (1990). The themes that emerged are discussed below in relation to the relevant survey questions.

\section{Results}

The research question for the faculty-wide study was to understand "What is happening in tutorials and how much is it costing the university", a study designed to identify areas of excellence and challenge, to evaluate it and to improve the tutorial system where required. The study was primarily designed for institutional educational development and costing purposes, but also offers a model for other faculties to review and evaluate their programmes, and some findings regarding good practices. The selected sub-study which is presented here aims to describe tutorials in the faculty of science in terms of their purpose, structure and approach, as well as their tutor training system. The research question was: "What form does the tutorial system at the university take, and what aspects are considered successful by those who run them?"

\section{The Faculty Context}

The size and shape of the faculty was supplied in Table 1; additionally, it should be mentioned that the student numbers per department varied between 285 and 9 829, emphasizing the different realities within the faculty. It should be mentioned that the student body is very diverse, but a large proportion of students are first generation students. The faculty taught 74 263 students in 2016 of whom 49,6\% were female students. The student population in 2016 is also described in ethnic terms, because of the economic and schooling disadvantages experienced by most students of colour in South Africa, who may therefore have been differently or less prepared for university study. The student population comprised of $48 \%$ ( $n=35$ 269) Black African students, 44\% ( $n=33$ 004) White students, 6\% (4 337) South African 
students of Indian origin, while the remaining $2 \%$ were Colored students, or those of mixed ethnic ancestry.

The results are presented in terms of the themes that were developed from the data.

\section{Tutorial Approach, Purpose, and Arrangements}

With regard to the survey question: "How are tutorials structured/what approach do they follow?" data about the role players, tutors' approaches, the duration and frequency of tutorials, and attendance, were collected. We identified and coded ten different approaches thematically. In Table 3, below, the summarized data is presented.

Table 3. Tutorial Approaches and Variations

\begin{tabular}{lc}
\hline Primary approach & No. \\
\hline $\begin{array}{l}\text { A worksheet gets completed as homework before the tutorial session starts and } \\
\text { then discussed in groups during the tutorial and the tutor assists where needed. }\end{array}$ & 1 \\
$\begin{array}{l}\text { A worksheet gets completed as homework before the tutorial session starts and } \\
\text { then is used as peer instruction using Clickers to see results. }\end{array}$ & 2 \\
$\begin{array}{l}\text { A worksheet gets completed as homework before the tutorial session starts and } \\
\text { then the solutions of some problems are discussed by the tutor. }\end{array}$ & 3 \\
$\begin{array}{l}\text { A worksheet gets done during the tutorial. } \\
\text { The practical sessions are done in combination with the tutorial and are repeated }\end{array}$ & 5 \\
$\begin{array}{l}\text { four times to accommodate all students. } \\
\text { The tutorial is used to prepare students for the practical session that follows }\end{array}$ & 6 \\
$\begin{array}{l}\text { directly afterwards. } \\
\text { Students watch video clips, then do dissections and then they have a tutorial to }\end{array}$ & 7 \\
$\begin{array}{l}\text { consolidate the experience during the practical session. } \\
\text { Tutorials are optional and students come to a scheduled period if they need to ask }\end{array}$ & 8 \\
$\begin{array}{l}\text { assistance. } \\
\text { The lecturer supplies real life scenarios in the tutorial session with problems to be }\end{array}$ & 9 \\
$\begin{array}{l}\text { solved, tutors assist with students who struggle. The lecturer wraps up the session } \\
\text { in the end. No test and also not compulsory attendance. }\end{array}$ & \\
They have large enrolment numbers and: “There are ten different tutorial sessions \\
per semester (presented as discussion classes). They last 2 hours and are based on \\
peer learning and Clicker questions with the purpose of better explaining difficult \\
$\begin{array}{l}\text { concepts from the theory. Attendance is compulsory and is monitored. Group size } \\
\text { is about } 60 \text { and I present the session without any tutors”. }\end{array}$
\end{tabular}

In Table 4, the dominant approach in each cluster in the faculty is shown as a percentage of the respondents in the cluster.

Table 4. Dominant Approach during Tutorials per Cluster

\begin{tabular}{|c|c|c|}
\hline $\begin{array}{l}\text { Cluster (number of } \\
\text { respondents)* }\end{array}$ & Dominant approach & $\%$ \\
\hline Mathematical (24) & $\begin{array}{l}\text { A worksheet received prior to the session } \\
\text { gets discussed during the session. }\end{array}$ & $71 \%$ \\
\hline Physical (15) & $\begin{array}{l}\text { A worksheet received prior to the session } \\
\text { gets discussed during the session. }\end{array}$ & $60 \%$ \\
\hline Biological (29) & Practical sessions get priority. & $80 \%$ \\
\hline Agricultural (14) & $\begin{array}{l}\text { Tutorial is used to prepare for practical or } \\
\text { to wrap up work done in practical. }\end{array}$ & $40 \%$ \\
\hline
\end{tabular}


Total respondents: 82

* The number of respondents is the number of completed questionnaires received. Some departments have a uniform approach in a number of modules and they therefore reported all the modules on one questionnaire. These results will reflect as one respondent.

In addition to asking about the approach, we asked lecturers: What is the purpose of your tutorials? Very diverse answers were received. Responses or codes included: "to sort out problems done in class" (R21 \& R40), "to do more textbook problems for practice” (R7), "to do enrichment work not covered during lectures" (R11), "we practice using questions from old exam papers" (R2), "an opportunity to explain difficult concepts again and better" (R54), "to prepare for practical session" (R56) to "write a concept test and then practice problems" (R30); (numbers in brackets refer to the respondents in the study). One lecturer reported: "We have a 2-hour session and during the first hour, they calculate the answers in groups with the assistance of the tutor. During the second hour the work is discussed by me. No answers or memorandum is supplied, only guidance. No assessment is done. I want it to be a meaningful learning opportunity. It should be stress free. I also do not check attendance, yet my class is full every week" (R1).

It became evident that the purpose of the tutorial (as formulated by the module coordinator) prescribed the teaching style of the tutorial, and as such emphasized the fact that tutorials should be integrated learning spaces. In Table 5, the most popular answers to the question about the purpose of tutorials are presented.

Table 5. Purpose of Tutorials

\begin{tabular}{llc}
\hline Cluster) & Purpose of tutorials & $\%$ \\
\hline Mathematical & Extra exercises to practise and to get active participation & $63 \%$ \\
Physical & To explain difficult concepts again and maybe differently & $27 \%$ \\
Biological & $\begin{array}{l}\text { To sort out problems that didn’t get time during lectures } \\
\text { To explain difficult concepts again and maybe differently }\end{array}$ & $20 \%$ \\
Agricultural & $\begin{array}{l}\text { (focus is on practical sessions) } \\
\text { problems in preparation for practical* }\end{array}$ & $14 \%$ \\
\hline
\end{tabular}

* There was no common answer that dominated in the Agricultural cluster.

Lecturers often used a test during tutorials to record attendance, while others used online quizzes before tutorials in a flipped-class manner. The question asked in the study was: What kind of assessment is done before, during or after the tutorial? There were mixed responses. One lecturer said: “I don't want them to stress the entire tutorial about the test that is coming, then they can't learn. I'd rather have them learn and do an online quiz later about the tutorial work" (R1). Four lecturers in a particular department explained that their class tests are written during tutorial periods and a few others explained that they prefer online post-tutorial tests as it lowers the marking load. Clickers are used to answer multiple choice questions in some modules and there is a module where students complete a pre- as well as a post-tutorial test.

In some of the larger departments, they rotate tutorials and practical sessions in a two-week cycle, and the tutorial is not compulsory. One lecturer wrote: "The students have a noncompulsory tutorial session every second week for three hours and if they have questions about the set of problems, they can attend the session. There are two tutors in the venue and the attendance fluctuate[s]" (R31). Yet, in the Mathematics department (with the highest enrolment figures), tutorials are compulsory since lecturers realize the important function they serve. One said: "It is in the tutorials that students get the chance to clarify their misconceptions. We write 
a small test at most of the tutorials to give us feedback about student understanding, but also feed back to them” (R43).

\section{Tutor Training}

On the topic of tutor training our question was: Describe the initial training and continued development offered to your tutors. Lecturers believe that the tutors are postgraduate students and as such they "know the work and should be able to conduct the tutorial without any assistance from me" (R5). In some of the larger departments, there is a system where "a senior tutor will oversee the other tutors in my module" (R8). Comments like these emphasize the fact that tutorials are not optimized as learning spaces when they are not conducted in an integrated manner. In some cases respondents noted that "all the tutors have to work out the exercise sheet and then they meet weekly (with either the lecturer or the most senior tutor with prior experience) where the memorandum is discussed and all potential problems highlighted" (R15). In one instance the tutors all attend the first tutorial of the week offered by the lecturer (R81). This lecturer understands the fact that a uniform approach is important and that the tutorials should be conducted as an integral part of the course. In Table 6 the summary of the responses about the training is shown. Other related questions were: "Do they get follow-up training (yes/no)" and "Describe the follow-up training”.

Table 6. Training Overview

\begin{tabular}{|c|c|c|c|}
\hline Cluster & Initial training & $\begin{array}{c}\text { Follow-up } \\
\text { (yes) }\end{array}$ & $\begin{array}{l}\text { Kinds of follow-up reported by } \\
\text { majority }\end{array}$ \\
\hline Mathematical & Nothing particular & $50 \%$ & $\begin{array}{l}\text { Weekly meetings, marking } \\
\text { assistance, memo to the } \\
\text { worksheet, senior tutor supports } \\
\text { them. }\end{array}$ \\
\hline Physical & $\begin{array}{l}\text { Training by the } \\
\text { AD* (Physics) or } \\
\text { nothing particular }\end{array}$ & $63 \%$ & $\begin{array}{l}\text { Ad hoc training as needed, } \\
\text { marking assistance, senior tutor } \\
\text { supports them. }\end{array}$ \\
\hline Biological & $\begin{array}{l}\text { Nothing particular } \\
\text { Training by the AD } \\
\text { ( } 2 \text { modules) }\end{array}$ & $69 \%$ & $\begin{array}{l}\text { Ad hoc as needed, one hour } \\
\text { weekly meeting, they get } \\
\text { memoranda. }\end{array}$ \\
\hline Agricultural & Nothing particular & $71 \%$ & Ad hoc training as needed. \\
\hline
\end{tabular}

* AD = academic developer

\section{Success Factors}

The last theme to be discussed in this paper arose from the question: "Why do you regard your tutorials as successful?” The question was the follow-up in a filter and follow-up question. The first part asked: "Do you regard your tutorials as successful?", and if they answered "yes", the "why" question was the follow-up question. In the pilot study $(n=11)$, all the respondents answered "yes", but in the questionnaire very few answered these questions at all, providing only a $22 \%$ response to this question. Eleven different codes were assigned and are supplied in Table 7, in most cases verbatim.

Table 7. Reasons for Tutorial Success

\begin{tabular}{lc}
\hline Reason supplied (Cluster: M, P, B or A*) & Frequency \\
\hline Stress free learning opportunity where misunderstandings are sorted out in time & 1 \\
(M) (R1) & \\
The way it is planned and conducted (M) (R5, R11, R12) & 3 \\
\hline
\end{tabular}


Opportunity to ask and clarify misunderstanding (M) (R7)

Increased confidence through interaction with tutors (M) (R10)

An opportunity to learn, but they do not attend, so NO gain for them (M) (R9)

The tutor attends class with me, so we look like a team (M) (R8, R19)

Opportunity to experience the software we use and tutor input (M) (R3) help (M) (R2, R4)

The student feedback indicates it (P) (R44-47)

They have tried the problems and know where they are stuck and then get help

(M) (R72)

The link between theory and practice becomes clear (B) (R29)

* M=Mathematical, $\mathrm{P}=$ Physical, $\mathrm{B}=$ Biological, $\mathrm{A}=$ Agricultural

\section{Discussion}

Previous research has identified that online activities combined with tutorials, either as a justin-time quiz before the tutorial, or as a post-tutorial activity, cause students to be more engaged and learn more (Finkelstein \& Pollock, 2005). However, it seems that not all lecturers plan their tutorials with strategies like this in mind. It became evident from questions about testing and the training of tutors that benefits would accrue if lecturers were to plan their tutorials as an integral part of the learning space, and not as an add-on, especially in this era where lecture groups are large and individual attention to students limited. When a lecturer uses a test to measure attendance, the test can easily be seen as the third voice in the ZPD, but if they give an online quiz later to judge the learning, it has a completely different aim and serves a good purpose.

The lecturers reported stark contrasts in attendance; one noted that that tutorials supply "no gain to students", because they do not attend (R69); yet in complete contrast to this, another lecturer reported that she has $90 \%$ of her class in her tutorials despite the fact that there is no form of assessment to force attendance; she, however, is present and offers discussion opportunities during the tutorial. This dichotomy demonstrates how the attitude of the lecturer towards the tutorial's purpose and the utilization of tutorials as learning spaces plays an important role in their ultimate success. Lecturers who promote the tutorial activities during lectures, and connect to them, reported better results.

There is evidence in the data above that many lecturers use tutorial tests or quizzes to deliberately break the hidden contract by, for example, having students complete an online, just-in-time quiz to determine their misconceptions about the content (Caldwell, 2007). This quiz can even act as a "warm-up" exercise for the tutorial, however, the biggest gain is that the tutor has access to students' typical misconceptions, and can guide the discussion towards solving them.

One lecturer alluded to the fact that the tutor, as an individual, determines the success of a tutorial (R69), and this fact raises the issue of training (survey question 2). The Department for Education Innovation has been mandated to train tutors in all faculties, yet training has not been made compulsory; as a result, some departments do not send their tutors for training at all. In 2015, only four departments out of 17 sent all of their tutors for training. The Department for Education Innovation cannot undertake any subject-specific training, but the value of the training lies in empowering tutors to deal with groups, to do effective question and answer sessions, to be sensitive to diversity, manage difficult students and keep students engaged. It is expected of departments to provide their tutors with academic support. The importance of coplanning (tutors and students coming to tutorials prepared), co-practice (recognizing that learning and emotions are interdependent), and co-evaluation (tutors and students reflecting on their involvement in the tutorials) becomes clear (see Table 2). 
The response rate for the question regarding why tutorials are regarded as successful was poor (22\%), but it is not possible to speculate about the reasons for that.

\section{Conclusion}

It is clear that lecturers need to carefully plan how they will use tutorials as learning spaces, but if students do not perceive them to add value, they will not attend. This study suggests that it would be valuable for tutors to reflect on their sessions weekly (co-evaluation) and to share their reflections with each other and the lecturers. Co-planning as seen by Murphy et al. (2015) could assist in optimizing the buds of development in tutorials. Furthermore, the study suggests that initial training offered to tutors should be non-negotiable, that they should be trained to engage emotionally and to handle wrong answers (co-practice). However, it is evident that continued support in terms of content knowledge should be emphasized as well. Lecturers could either let tutors complete the worksheet prior to a weekly meeting, or expect that all tutors attend the first session each week as was suggested by one lecturer in the data above (R81). The moment lecturers regard tutorials as an integral part of the learning experience, they look differently at their own as well as the tutors' roles and planning becomes more integrated with the lecture presentation style. This study further suggests that it is pedagogically unacceptable to place an under-prepared tutor in charge of a large class of first-year students.

\section{Acknowledgement}

This paper was written with the support of funding from the South African Department of Higher Education and Training National Collaborative Teaching Development Grant (TDG) Project: The improvement of teaching and learning in South African universities through researching and evaluating Teaching Development Grant projects in the First Year Experience (FYE) initiatives, Tutorials, Mentoring and Writing Retreats. My sincerest gratitude to Moragh Paxton and Lucy Alexander for their comments on earlier drafts, and Jenny Birkett for proofreading this article.

\section{Disclosure Statement}

No potential conflict of interest was reported by the author.

\section{Notes on Contributor}

Ina Louw has been an academic developer at the University of Pretoria since 2014. She was previously a mathematics lecturer for almost 30 years at a university of technology. She obtained a $\mathrm{PhD}$ in the field of mathematics education and her research interests are science education and staff development.

\section{References}

Ageyev, V. S. (2003). Vygotsky in the mirror of cultural interpretations. In A. Kuzulin, B. Gindis, V. S. Ageyev, \& S. M Miller (Eds.), Vygotsky's educational theory in cultural context (pp. 432-449). Cambridge, England: Cambridge University Press.

Bianco, C. (2005). Online tutorials: Tips from the literature. Library Philosophy and Practice, 8(1). Retrieved from http://digitalcommons.unl.edu/libphilprac/65

Brockbank, A., \& McGill, I. (1998). Facilitating reflective learning in higher education, London, England: Society for Research into Higher Education and Open University Press.

Brogt, E. (2007). A theoretical background on a successful implementation of lecture-tutorials. Astronomy Education Review, 6(1), 50-58. doi: 10.3847/AER2007005

Caldwell, J. E. (2007). Clickers in the large classroom: Current research and best-practice tips. CBE Life Sciences Education, 6, 9-20. doi: 10.1187/cbe.06-12-0205 
Chickering, A. W., \& Ehrmann, S. C. (1996). Implementing the Seven Principles: Technology as lever. AAHE Bulletin, October 1996. Retrieved from http://www.aahebulletin.com/public/archive/sevenprinciples.asp?pf=1

Cohen, L., Manion, L., \& Morrison, K. (2000). Research methods in education (1st ed). London, England: Routledge Falmer.

Eun, B., Knotek, S. E., \& Heining-Boynton, A. L. (2008). Reconceptualizing the zone of proximal development: The importance of the third voice. Educational Psychology Review, 20, 133-147. doi: 10.1007/s10648-007-9064-1

Falchikov, N. (2001). Learning together. Peer tutoring in higher education. London, England: Routledge Falmer.

Finkelstein, N. D., \& Pollock, S. J. (2005). Replicating and understanding successful innovations: Implementing tutorials in introductory physics. Physical Review Special Topics - Physics Education Research, 1, 1-13. doi: 10.1103/PhysRevSTPER.1.010101

Ghosh, S. (2007). Combination of didactic lectures and case-oriented problem-solving tutorials toward better learning: perceptions of students from a conventional medical curriculum. Advances in Physiology Education, 31(2), 193-197. doi: 10.1152/advan.00040.2006

Gilkison, A. (2003). Techniques used by “expert” and "non-expert” tutors to facilitate problembased learning tutorials in an undergraduate medical curriculum. Medical Education, 37, 6-14.

Louw, C. J. (2003). Die impak van tutoriale op die wiskundeprestasie van student in eerstejaarswiskunde [The impact of tutorials on the mathematics achievement of first year students in mathematics] (Masters dissertation). Retrieved from http://hdl.handle.net/2263/24368

McDermott, L. C., Shaffer, P. S., \& Constantinou, C. P. (2000). Preparing teachers to teach physics and physical science by inquiry. Physics Education, 35(6), 411-416. Retrieved from http://iopscience.iop.org/0031-9120/35/6/306

Murphy, C., Scantlebury, K., \& Milne, C. (2015) Using Vygotsky's zone of proximal development to propose and test an explanatory model for conceptualising coteaching in pre-service science teacher education. Asia-Pacific Journal of Teacher Education, 43(4), 281-295. doi: 10.1080/1359886X.2015.1060241

Nieuwenhuis, J. (2011). Qualitative research designs and data gathering techniques. In K. Maree (Ed.), First steps in research (70-92). Pretoria, South Africa: Van Schaik Publishers.

Palincsar, A. S. (1998). Keeping the metaphor of scaffolding fresh - a response to C. Addison Stone's “The metaphor of scaffolding: Its utility for the field of learning disabilities". Journal of Learning Disabilities, 31, 370-373. doi: 10.1177/002221949803100406

Papinczak, T., Tunny, T., \& Young, L. (2009). Conducting the symphony: a qualitative study of facilitation in problem-based learning tutorials. Medical Education, 43, 377-383. doi:10.1111/j.1365-2923.2009.03293.x

Swanepoel, E. 2016. Matriekpunte was eintlik 10\% laer [Matric marks were actually 10\% lower]. Rapport, 13 March: 9.

Scott, I. (2009). First-year experience as terrain of failure or platform for development? Critical choices for higher education. In B. Leibowitz, A. Van der Merwe, \& S. Van Schalkwyk (Eds.), Focus on first-year success: Perspectives emerging from South Africa and beyond (pp.17-36). Stellenbosch, South Africa: SUN Press.

Steinberg, R. N. (2000). Computers in teaching science: To simulate or not to simulate? American Journal of Physics, 68(7), S37-S41.

Tesch, R. (1990). Qualitative research: Analysis types and software tools. New York, United States of America: Falmer. 
Underhill, J., \& McDonald, J. (2010). Collaborative tutor development: Enabling a transformative paradigm in a South African university. Mentoring \& Tutoring: Partnership in Learning, 18(2), 91-106. doi: 10.1080/13611261003678853

University of Pretoria. (2016). Research in the Faculty of Natural and Agricultural Sciences. Retrieved from http://www.UP.ac.za/en/faculty-of-Natural-and-agriculturalsciences/article/16184/research

Van Wyk, B.J., Hofman, W.A.H., \& Louw, I. (2015). Impact of mathematics and physical science on the success of South African engineering technology students. International Journal of Engineering Education, 31(4), 1158-1166. Retrieved from http://www.ijee.ie/contents/c310415.html

Vygotsky, L.S. (1978). Mind in society, Cambridge, MA: Harvard University Press, 79-91.

Yin, R.K. (1984). Case study research: Design and methods. Beverly Hills, CA: Sage Publications. 